\title{
HIPÓTESE DO CULTIVO MIDIÁTICO E A CULTIVAÇÃO DE NOVOS MODOS DE NARRAR
}

Kyldes Batista Vicente*

\begin{abstract}
Resumo: Estudos sobre o impacto da televisão na vida dos telespectadores têm despertado o interesse de estudiosos da comunicação, da psicologia, da sociologia. Muitos defendem a influência nociva deste meio na construção do ser humano, na formação da criança. No entanto, muitos estudos também têm mostrado que os programas televisivos nem sempre são os responsáveis pela formação de opinião. O presente trabalho pretende discutir aspectos da hipótese do cultivo midiático e do conceito de habitus (em Bourdieu) para levantar questionamentos acerca da cultivação de novos modos de produzir teledramaturgia. Para isso, partimos de alguns produtos elaborados sob a direção de Luiz Fernando Carvalho: Os Maias (2001), A Pedra do Reino (2007) e Capitu (2008). A escolha das minisséries se justifica pelo fato de terem sido produzidas com um alto padrão e não atingido o índice esperado de audiência.
\end{abstract}

Palavras-chave: cultivo midiático, teledramaturgia, consumo.

Muitas pesquisas têm se preocupado em observar a influência, o impacto da televisão na vida dos telespectadores. A hipótese do Cultivo Midiático é uma das teorias utilizadas nos estudos dos efeitos da televisão. Originário do latim cultivare, o termo cultivar refere-se ao fato de fertilizar (a terra) pelo trabalho; dar condições para o nascimento e desenvolvimento de (planta). De forma figurativa, pode ser entendido como procurar formar; desenvolver; aplicar-se ou dedicar-se a; procurar manter ou conservar; formar, educar ou desenvolver pelo estudo, pelo exercício; formar-se pela educação; adquirir cultura. Processo de enculturação: "Processo de condicionamento e/ou de aprendizagem, consciente ou inconsciente, formal ou informal, mediante o qual um indivíduo, no decorrer da vida, apreende os padrões gerais de sua cultura; socialização.” (Dicionário Aurélio Eletrônico).

A hipótese do Cultivo Midiático, que para Gerbner e outros (ㅁpud CARDOSO FILHO, 2007) pode ser definida como "um contínuo e dinâmico processo de interação entre mensagens, audiências e contextos”, foi desenvolvida a partir de um projeto que pretendia entender a forma como os indivíduos se desenvolviam em ambiente centrado na televisão, expostos a notícias e conteúdos de violência. Este grupo de pesquisadores defendeu a idéia de que "a realidade transmitida pela mídia pode influenciar crenças e, consequentemente, a conduta. Eles chamam isso de 'levar na corrente’. Em termos de televisão, sugerem que seu conteúdo 'desenvolve’ as crenças nas pessoas” (DEFLEUR; BALL-ROKEACH, 1993: 282-3): a hipótese do Cultivo Midiático está relacionada à teoria dos efeitos de socialização:

\footnotetext{
* Mestre em Letras e Linguística (UFG), aluna do Programa de Pós-Graduação em Comunicação e Cultura Contemporâneas - Doutorado (UFBA), professora de Literatura Portuguesa (UNITINS), kyldesv@gmail.com
} 
Segundo uma perspectiva individual, a socialização equipa-nos para comunicar, pensar e resolver problemas utilizando técnicas aceitáveis pela sociedade, e, de maneira geral, para conseguirmos nossas adaptações singulares a nosso ambiente pessoal. Do ponto de vista da sociedade, a socialização leva seus membros a um conformismo suficiente, de modo a poderem ser preservadas a ordem social, a previsibilidade e a continuidade. Grifos do autor (DEFLEUR; BALL-ROKEACH, 1993: 226)

É a partir da socialização que cada indivíduo estabelece a interiorização de normas, práticas e valores da sociedade, dos modos de comportamento, estabelecendo formas de pensar e de agir do grupo em que o indivíduo está inserido. Daí ser considerado um processo de aprendizagem no qual, por meio da interiorização dessas normas e valores comuns, é estabelecida a integração social.

Nessa perspectiva, um indivíduo já socializado é introduzido em novos setores da sociedade: na escola, nos grupos de amigos, no trabalho, nas atividades de países visitados, etc. Há uma aprendizagem das expectativas que a sociedade, ou o grupo social, deposita em nós em relação ao nosso desempenho. Assim também ocorre nos novos papéis que vamos assumindo nos vários grupos a que vamos pertencendo e nas diferentes situações em que somos colocados. Com isso, a assimilação de linguagens, valores, normas, julgamentos permite aos indivíduos a socialização. O que a antropologia vai chamar de enculturação.

Enculturação esta que Gerbner irá considerar ao ver a televisão como elemento cultivador de um processo dinâmico e contínuo de efeitos sob os telespectador. A televisão é responsável por partilhar a maior parte dos referenciais da sociedade contemporânea. Gerbner defende que são os efeitos a longo prazo e não os efeitos a curto prazo os considerados na análise da hipótese do Cultivo Midiático. Isso é possível pelo fato de a estrutura dos programas televisivos estar centralizada em narrativas, o que leva mensagens com relativa coerência ao telespectador. Essas informações, estruturadas em narrativas, constroem opiniões, juízos de valor e modelos de comportamento.

Em suas pequisas sobre a hipótese do Cultivo, estudiosos como Chris Segrin, Robin Nabi, Oscar Gandy Jr., Jonathan Baron aplicaram a “teoria” para buscar respostas a questões relacionadas à influência a longo prazo da televisão em telespectadores assíduos. Chris Segrin e Robin Nabi (2002) pesquisaram as expectativas idealizadas sobre o casamento e sobre intenções de casar em adolescentes, supondo que estes jovens teriam como principal influenciador os programas de televisão. Neste caso, no entanto, não foi levando em consideração pelas autoras o fato de a concepção romântica dos adolescente ser gerada por outros atores da sociedade. O efeito a longo prazo também não foi considerado nesta pesquisa. Já para procurar entender que efeitos são os que a televisão pode cultivar em seus telespectadores assíduos, Oscar Gandy Jr. e Jonathan Baron (1998) articulam a hipótese do Cultivo ao Framing. 
O propósito deste texto, no entanto, não é procurar entender a hipótese do Cultivo Midiático. Neste texto, a partir dos elementos que dão origem às pesquisas que consideram a televisão como capaz de cultivar determinados hábitos, gostos e/ou valores, objetivamos estender nossa discussão à idéia de habitus (em Pierre Boudieu).

Como exemplo, tomaremos as minisséries Os Maias, Pedra do Reino e Capitu, produzidas sob a direção de Luiz Fernando Carvalho, para tratar desses aspectos de enculturação em alguns produtos da televisão brasileira. Por trás da leitura de um produto midiático há que se considerar o valor vinculado àquele produto. O produto e seu valor não podem, no entanto, ser considerados separados do lugar de onde são gerados: o espaço social. Este é construído para que grupos e agentes sejam distribuídos em função da posição que ocupa, a partir de seu capital econômico e cultural.

A cada classe de posições corresponde uma classe de habitus (ou de gostos) produzidos pelos condicionamentos sociais associados à condição correspondente e, pela intermediação desses habitus e de suas capacidades geradoras, um conjunto sistemático de bens e de propriedades, vinculadas entre si por uma afinidade de estilo. (BOURDIEU, 2007: 21)

Bourdieu (2007) completa esta idéia afirmando que estabelecer unidade de estilo das práticas e dos bens de determinada classe de agentes é uma das funções do habitus, cujo estabelecimento de um princípio unificador traduz o conjunto das escolhas de pessoas, bens e práticas.

Os habitus são princípios geradores de práticas distintas e distintivas - o que o operário come, e sobretudo sua maneira de comer, o esporte que pratica e sua maneira de praticá-lo, suas opiniões políticas e sua maneira de expressá-las diferem sistematicamente do consumo ou das atividades correspondentes do empresário industrial. Eles estabelecem as diferenças entre o que é bom e o mau, entre o bem e o mal, entre o que é distinto e o que é vulgar etc., mas elas não são as mesmas. (BOURDIEU, 2007: 22)

Essas escolhas, de acordo com Bourdieu, são percebias a partir da percepção de seu espaço social.

ao serem percebidas por meio dessas categorias sociais de percepção, desses princípios de visão e de divisão, as diferenças nas práticas, nos bens possuídos, nas opiniões expressas tornam-se diferenças simbólicas e constituem uma verdadeira linguagem. (BOURDIEU, 2007: 22)

Retomando os elementos da hipótese do Cultivo Midiático, podemos considerar que os telespectadores da teledramaturgia seriada brasileira foram cultivados a reconhecer algumas marcas valorativas. Assim, telenovelas e minisséries produzidas pela Rede Globo de Televisão possuem determinados elementos que se configuram com seu padrão.

Ao partir de elementos da narratividade, a relação temática com o cotidiano, os ideais de amor, elementos da realidade ligados à ficção, o suspense, os segredos e mentiras fazem da 
narrativa televisiva um espaço de estabelecimento de cumplicidade com o telespectador. Esse espaço é cultivado gradativamente com apresentação gradual de temas, situações e personagens polêmicas. Enfim, o habitus do telespectador é cultivado.

O habitus deve ser compreendido como uma gramática gerativa de práticas conformes com as estruturas objetivas de que ele é produto: a circularidade que preside sua formação e seu funcionamento explica, por um lado, a produção de regularidades objetivas de comportamento; por outro, a modalidade de práticas baseadas na improvisação, e não na execução de regras. Juntando dois aspectos, um objetivo (estrutura) e outro subjetivo (percepção, classificação, avaliação), pode-se dizer que ele não só interioriza o exterior, mas também exterioriza o interior. (PINTO, 2000: 38)

É nessa perspectiva que retomamos Bourdieu (2007: 14) ao se referir aos elementos de produção cultural:

Os campos de produção cultural propõem, aos que neles estão envolvidos, um espaço de possíveis que tende a orientar sua busca definindo o universo de problemas, de referências, de marcas intelectuais [...] Esse espaço de possíveis, que transcende os agentes singulares, funciona como uma espécie de sistema comum de coordenadas que faz com que, mesmo que não se refiram uns aos outros, os criadores contemporâneos estejam objetivamente situados uns em relação aos outros.

A produção de teledramaturgia, especialmente a minissérie, teve a sua inauguração em meados da década de 1980, quando a Rede Globo inaugurou esse novo formato de programa. Semelhante às novelas, só que mais curtas, geralmente suas produções demandam custos muito altos. Geralmente são exibidas depois das 22h. É neste horário que a emissora investe em novas tecnologias, como o uso da filmagem em película. Ao todo, já foram produzidas mais de noventa minisséries pela emissora. Das minisséries produzidas de 1984 até 2008, trinta e cinco foram feitas tendo por base textos literários, a maioria de autores do século XIX e alguns considerados clássicos da literatura contemporânea. Guimarães (2003: 97) afirma que a "ficção televisiva privilegia obras de narrativa linear e enredo movimentado" em que narrativas "repletas de acontecimentos e reviravoltas” dão suporte à "forte carga sentimental e melodramática e um pano de fundo composto de períodos ou episódios históricos relevantes e reconhecíveis pelo espectador”.

Para a minissérie Os Maias (2001), o trabalho de pesquisa da equipe de produção sobre as obras de Eça de Queirós, sobre o percurso do escritor, o envolvimento dos atores, a presença de críticos de Eça no contexto da produção de cada capítulo, o investimento, o figurino, a trilha sonora, enfim, os elementos que transpuseram o romance português do século XIX para a tela brasileira não deixavam dúvida sobre o sucesso. E mais: a incorporação de outros dois textos do mesmo romancista: A Relíquia e A Capital dariam ao texto audiovisual mais dinâmica, mais ação que a televisão requer. As peripécias de Teodorico e de sua Titi, personagens de A Relíquia, adicionam a comicidade à minissérie. No entanto, a narrativa lenta do romance e do ambiente aristocrata 
português foram incorporados ao texto audiovisual e não agradou ao público. A Folha de São Paulo publicou, na época, alguns comentários sobre a produção da minissérie:

A minissérie ‘Os Maias’ estréia hoje na Globo com uma missão especial: oferecer biscoito fino para as massas. A história, baseada no livro homônimo do escritor português Eça de Queirós, terá 44 capítulos. A direção é de Luiz Fernando Carvalho. A adaptação, de Maria Adelaide Amaral.

'Quero fazer uma obra 'assistível', mas sem banalizar ou vulgarizar o romance. O maior objetivo é trazer o público para a minissérie. Não o contrário’, afirma Maria Adelaide Amaral. [...]

Para Amaral, minisséries são oportunidades raras de realizar um trabalho denso. Geralmente pode-se gastar três, quatro dias para escrever um capítulo, enquanto um autor de novela tem apenas um dia.

A diferença de orçamento também garante melhor acabamento. $\mathrm{O}$ orçamento médio de um capítulo de novela é de R 100 mil. O de uma minissérie é o dobro: R \$ 200 mil. 'Os Maias' estourou em $10 \%$ esse orçamento e custou quase R $\$ 10$ milhões no total.

É a produção da Globo que passou mais tempo sendo gravada fora do Brasil. Durante seis semanas, o elenco e a equipe técnica estiveram em várias cidades de Portugal. Tudo para evitar ao máximo o clima artificial de estúdio. (Christian Klein, Folha Online)

Apesar de sucesso de crítica, o elogiado figurino, a trilha sonora, a audiência não satisfez as expectativas. Apesar de ser um dos grandes romances da literatura portuguesa, a minissérie Os Maias recebeu críticas severas de telespectadores e críticos: a reclamação pela irregularidade do horário de exibição dos capítulos circulou entre as maiores críticas.

Segundo Hélio Guimarães (2003), a adaptadora e o diretor da minissérie atribuíram a baixa audiência ao estranhamento com a alta qualidade dos capítulos, o que estaria em contraste com a maioria dos programas televisivos. Já a Academia Brasileira de Letras foi a maior defensora da minissérie, argumentando sobre a importância da adaptação para despertar para a leitura do livro.

No texto Sobre a Televisão, Bourdieu (1997) aponta os mecanismos de funcionamento do campo televisivo e seus efeitos. Segundo ele, a lógica de produção televisiva requer produção de algo que seja extraordinário, desencadeando homogeneidade da produção e pouca autonomia para seus produtores. Outro efeito ocasionado pela pressão pelo índice de audiência é a urgência, a rapidez, a velocidade. Esta pressão pelo mercadológico impõe-se também em outros campos por influência da televisão, principalmente no campo artístico pela lista de best-sellers. No entanto, não foi isso que aconteceu com a minissérie Os Maias: todo processo de produção obedeceu a um processo de elaboração e pesquisa da adaptadora, do diretor e dos atores.

Segundo Jauss (1993), o produto cultural é desenvolvido a partir de um horizonte de expectativas para seus receptores, formadas a partir de um conjunto de padrões que servem como referência para recusa ou absorção de uma nova obra. A absorção de uma nova obra se dará a partir da adequação dela ao horizonte de expectativas do receptor. 
Quando um produto é recusado pela audiência, não há adequação entre horizonte e obra. Assim, é possível que o público realmente tenha estranhado a produção estética, a narrativa, a linguagem de Os Maias pelo fato deste não ser o padrão das atrações televisivas, o que rompe com a percepção do telespectador.

Carlos Reis, estudioso de Eça de Queirós, foi convidado pela Rede Globo para dar assessoria ao elenco e à equipe de produção da minissérie Os Maias. Após “testemunhar o cuidado quase obsessivo que está a ser posto na reconstituição de cenários, de adereços, de figurinos e de tudo o mais que pode incutir à realização (de Luiz Fernando Carvalho) uma autenticidade e uma identificação epocal acentuadíssimas”, publica um texto em que discute alguns dados sobre a adaptação do romance português para a televisão brasileira:

É claro que, com tudo isto (ou apesar de tudo isto), Os Maias na televisão enfrentam os riscos de uma missão impossível. Antes de mais, haverá por certo uma resistência inicial do espectador português (como aconteceu com O Primo Basílio, há anos) relativamente ao sotaque brasileiro com que nos falarão Afonso da Maia e Eusebiozinho, Maria Eduarda e Palma Cavalão, Carlos Eduardo e João da Ega; penso, contudo, que a habituação (a competência narrativa, pode dizer-se) do espectador de telenovelas e de séries brasileiras rapidamente neutralizará esse handicap. (REIS, 2000)

O professor de literatura da Universidade de Coimbra e autor de inúmeros livros sobre Eça de Queirós tinha algumas preocupações acerca de como o telespectador iria receber todo o apuro na reconstituição de uma época: o público iria identificar-se com personagens, ambientes e a narrativa? Mesmo com a inserção de um enredo cômico, personagens “vistosas” e um elenco experiente, Carlos Reis temia a recepção do telespectador. No entanto, a astúcia narrativa da adaptadora, a dedicação dos atores e o obsessivo cuidado da direção não foram suficientes para marcar os índices esperados de audiência.

Alguns críticos falaram da lentidão narrativa imprimida na minissérie, como uma reprodução do ritmo romanesco. Outros optaram por desaprovar a junção de outros textos de Eça de Queirós. Telespectadores reclamaram do horário de exibição, conforme aludido anteriormente. O que nos interessa, neste trabalho, é apontar essa forma narrativa (tão criticada por muitos) como uma possível estratégia de habituação do telespectador brasileiro.

Seis anos após a minissérie Os Maias, Luiz Fernando Carvalho traz ao telespectador brasileiro mais uma minissérie adaptada de uma obra literária: Pedra do Reino (2007). Neste trabalho, temos indicações de que o diretor traz elementos da teatralidade para a televisão. O texto de Ariano Suassuna apresenta elementos pouco típicos para a televisão, como podemos ver no trecho a seguir, publicado à época da exibição da minissérie:

A inovação de “A pedra do reino” não pára por aí. Luiz Fernando Carvalho propõe um novo formato de teledramaturgia. "Não tem início, meio e fim; cada episódio tem vida própria, independente, mas, ao mesmo tempo, o conjunto tem uma unidade que faz sentido no 
universo labiríntico do Ariano”, explica. (Entrevista a Carla Meneguini, G1)

Em entrevista a Carlos Helí de Almeida, da JB Online, sobre a microssérie Capitu (2008), Luiz Fernando Carvalho é questionado sobre a característica de seu trabalho:

Você optou por uma narrativa linear. Já andam dizendo que este é o seu trabalho mais palatável, digerível, ou mesmo popular, apesar dos diálogos do século 19 e as intervenções do narrador. Considera um elogio?

Não estou correndo atrás de elogios; por outro lado, ainda tenho as costas cheias de cicatrizes por ter feito A Pedra do Reino como fiz, e, sinceramente, buscava com o romance de Ariano Suassuna a mesma comunicação que busco agora com Machado de Assis. Não me guio pelo que é ou não palatável, me guio pela vida, com todos os riscos que isso possa ter. Às vezes o que produzimos reencontra a vida, outras nem tanto.

Em outro momento, diz que não faz cinema aos quilos e que não está preocupado com a audiência:

O Projeto Quadrante foi criado com o objetivo de transpor para a televisão obras literárias que possibilitem uma reflexão sobre a cultura brasileira - independentemente do retorno em termos de audiência. Qual o próximo projeto do programa?

Primeiro, permita-me esclarecer uma coisinha: eu recebo a mesma pressão por audiência que qualquer diretor, certo? Não sou daqueles que fazem fita, a coisa pesa e muito para o meu lado. E não poderia ser de outro jeito, minha busca é conciliar qualidade, a responsabilidade cultural que acredito que a televisão ainda precisa abraçar mais e melhor, e a comunicação de que falo sempre. O resto é balela. Quanto ao Quadrante, seguiremos com Dançar Tango em Porto Alegre, do Sérgio Faraco, este o Quadrante do Rio Grande do Sul, e depois Dois Irmãos, do Hatoum. (Entrevista a Carlos Helí de Almeida, JB Online)

A preocupação com a responsabilidade cultural e a qualidade são elementos que prenunciam uma tentativa de trazer ao telespectador aquilo que “a televisão ainda precisa abraçar melhor”:

OP - O apuro com a experiência visual sempre foi forte em seus trabalhos e se apresenta mais uma vez aqui. Que cuidados você tomou para não transformar a imagem em fetiche em Capitu?

Carvalho - Não costumo acreditar em apuros técnicos, muito ao contrário, se o espectador prestar bem atenção nas minhas imagens vai perceber que, isoladamente, uma a uma, elas contêm uma enorme quantidade de erros. O que dá algum sentido de beleza a elas é a montagem e a atuação dos atores. Um intérprete simplesmente bonito não traz em si a beleza. Uma luz bem posicionada não nos dá naturalmente a atmosfera vital de um instante. Veja os comerciais de geladeira, estão repletos de azuis brilhantes, tecnicamente muito bem apurados, mas é um apuro "de plástico" e não um apuro plástico. Por outro lado, poderia até dizer que o conjunto de imagens que Bentinho reúne e consagra de Capitu acabam por transformá-la em um fetiche, sim. (O Povo Online)

O sucesso da narrativa serial está na repetição de um esquema, de uma estrutura narrativa. Os juízos de valor e de gosto do telespectador estão ligados não só à temática apresentada pelo produto, mas também à estrutura que ela apresenta. No entanto, essa narrativa seriada construída pela direção de Luiz Fernando Carvalho se vale da autoreferencialidade, mas causa estranhamento. Trabalha com nossas expectativas cinematográficas, mas trabalha com a ruptura dessas expectativas: na relação entre imagem e som, na construção da imagem cinematográfica. A obra 
indica seus modos potenciais de leitura, propondo uma leitura estética. A junção de elementos temáticos, emocionais, estruturais faz desenvolver essa ruptura.

O espectador também torna-se formador da sensibilidade que se tem a partir da relação com a sociedade. E ainda há que se considerar o contexto social em que é construído, como afirma Simon Frith (1996):

to undestand cultural value judgements we must look at the social contexts in which they are made, at the social reasons why some aspects of a sound or spectacle are valued over others; we must understand the appropriate times and places in which to voice such judgments, to argue them. (FRITH, 1996: 22)

Os espectadores estariam, então, mais interessados no prazer neobarroco da forma, do que propriamente do conteúdo da teledramaturgia?

Umberto Eco (1989), no texto O texto, o prazer, o consumo, ao discutir o leitor modelo, levanta alguns questionamentos acerca do que faz uma obra de sucesso. No texto em questão, Eco afirma que

Um livro obtém sucesso somente em dois casos: se dá ao público o que ele espera ou se cria um público que decide esperar o que o livro lhe dá. Ou seja, toda obra 'pequena' atende às solicitações do público que a individualizou, ao passo que toda 'grande' obra cria as solicitações do público que decide formar. (ECO, 1989: 104)

No caso do livro, o autor torna-se um sucesso a partir da sua relação com o público. A criação literária de José Saramago, por exemplo, ao seu modo, propõe uma ruptura com a linearidade da produção narrativa. Saramago rompe com alguns elementos da estrutura da narrativa modificando seu modo narrativo que, para ele, aproxima-se da oralidade. O leitor iniciante de Saramago estranhará a forma como são apresentadas as personagens e como a inserção dos diálogos é construída. No entanto, José Saramago estabeleceu uma relação com seu público: cultivou nos leitores um habitus.

Ao apresentar elementos de análise da recepção de telenovelas, Souza (1998) aponta-nos um questionamento importante. Segundo ela,

O ritual de consumo das telenovelas estabeleceu-se nos anos 60. Reporta-se, portanto, a um campo artístico e a um mercado televisivo já constituídos que implicavam a contínua construção de um público consumidor desse bens simbólicos. Mas, mais do que isso, reporta-se a emissoras que tinham como prerrogativa básica para os seus projetos de consolidação e expansão um acompanhamento meticuloso do seu público consumidor. Não só porque ele deveria existir enquanto tal, mas também porque não poderia morrer, devendo portanto ser permanentemente construído. Esse processo de construção do público pelas emissoras (ou por qualquer outra instituição mediática) não é uma particularidade do momento de constituição do campo artístico; contudo, o estado de campo é um dos elementos que auxiliam sua compreensão, manutenção e expansão. (SOUZA, 1998: 77)

Isso nos leva a crer que o telespectador sempre foi "acostumado” a consumir determinado produto. Esse ritual de consumo, como apresenta Souza (1998: 78), parte da construção do espaço 
social, definido por Bourdieu (2007) como “estrutura de posições diferenciadas, definidas, em cada caso, pelo lugar que ocupam na distribuição de um tipo específico de capital”.

Com isso, levantamos questionamentos acerca de uma tentativa de Luiz Fernando Carvalho de estabelecer, a partir do cultivo, um novo olhar acerca da direção de produtos televisivos. Nosso propósito não é afirmar ou negar um possível estabelecimento de um habitus. Ao contrário, quisemos discutir a presença da constante direção de Luiz Fernando Carvalho, em horário nobre e com grandes investimentos. Questionar não no sentido da qualidade, mas no aspecto da audiência. Os produtos divulgados por Carvalho primam pela elaboração, cuidado e respeitabilidade. O padrão Globo de televisão poderia estar em busca de um novo olhar para seus produtos? Não é gratuita a presença deste respeitado diretor. A televisão brasileira estaria cultivando novos hábitos nos consumidores de teledramaturgia? Para ter tal resposta, o tempo deverá ser considerado e só o futuro negará ou reafirmará o efeito cultivado.

\section{Referências}

BOURDIEU, P O poder simbólico. 2ed. Rio de Janeiro: Bertrand Brasil, 1998.

. Razões Práticas: sobre a teoria da ação. 8ed. Campinaa: Papirus, 2007. . As Regras da Arte. São Paulo: Cia. Das Letras, 1996.

. Sobre a Televisão. Rio de Janeiro: Jorge Zahar, 1997.

CARDOSO FILHO, J L C. Cultivo mediático e suas conseqüências: um problema e duas propostas para análise dos efeitos dos media. In: Revista Contemporânea. vol 5. n. 1 e 2. Dez. 2007.

CARVALHO, L F. Sobre o filme Lavoura Arcaica. Cotia: Ateliê Editorial, 2002.

CALABRESE, O. A Idade Neobarroca. Lisboa: Martins Fontes, 1988.

C SEGRIN, R L. N. Does Television Viewing Cultivate Unrealistic Expectations About Marriage?. Journal of Communication. vol 52, Number 2 (June 2002), p. 247-263.

DEFLEUR, M.; BALL-ROKEACH, S. Teorias da Comunicação de Massa. 5ed. Rio de Janeiro: Jorge Zahar, 1993.

DICIONÁRIO AURÉLIO ELETRÔNICO. Versão 3.0.

ECO, U. Sobre os Espelhos e outros ensaios. 3ed. Rio de Janeiro: Nova Fronteira, 1989.

FRITH, S. Performing Rites: on the value of popular music. Havard Press University: Massachusetts, 1996.

K. GROSS, S. ADAY. The Scary World in Your Living Room and Neighborhood: Using Local Broadcast News, Neighborhood Crime Rates, and Personal Experience to Test Agenda Setting and Cultivation. Journal of Communication. vol 53. n 3. 2003. p. 411-426.

GUIMARÃES, H. O romance do século XIX na televisão: observações sobre a adaptação de Os Maias. In. PELLEGRINI, T et. al. Literatura, cinema e televisão. São Paulo: Senac/Instituto Itaú Cultural, 2003.

JAUSS, H. R. A literatura como provocação. Lisboa: Passagens, 1993.

PINTO, L. Pierre Bourdieu e a teoria do mundo social. Rio de Janeiro: FGV, 2000. 
R.L. NABI, J.L. SULLIVAN. Does Television Viewing Relate to Engagement in Protective Action Against Crime? A Cultivation Analysis From a Theory of Reasoned Action Perspective. Communication Research. vol 28. n 6. 2001. p. 802-825.

REIS, C. Os Maias na TV: missão impossível 2? In. Jornal de Letras, Artes e Ideias. Outubro de 2000.

SEGRIN, C.; NABI, R.. Does Television Viewing Cultivate Unrealistic Expectations About Marriage? Journal of Communication. vol 52. n 2. 2002. p.247-263.

WOLF, M. Teorias da Comunicação de Massa. 4ed. Lisboa: Presença, 1995.

A pedra do reino revela universo encantado de Ariano Suassuna. Globo.com. Disponível em: http://g1.globo.com/Noticias/PopArte/0,,MUL50062-7084,00.html.

Entrevista com Luiz Fernando Carvalho. Carlos Helí de Almeida. JB Online. Disponível em http://jbonline.terra.com.br/extra/2008/12/05/e05129369.html.

Entrevista com Luiz Fernando Carvalho. O Povo Online. Disponível em http://jbonline.terra.com.br/extra/2008/12/05/e05129369.html.

“Os Maias” quer dar a Eça ares de cinema", Cristian Klein copyright. Folha de S. Paulo, 9/01//01. Disponível em: http://www.observatoriodaimprensa.com.br/atualiza/artigos/qtv150120014.htm. 